\title{
Prevalence on the Early Loss of Primary Molars and Indication for Space Maintainers
}

\author{
Lakshmi Lakshmanan, Ganesh Jeevanandan* and EMG Subramanian \\ Postgraduate student Department of Pedodontics Saveetha Dental College and Hospitals Saveetha \\ Institute of Medical and Technical Sciences Saveetha University Chennai 77, India \\ Corresponding author email: ganesh.sdc@saveetha.com
}

\begin{abstract}
The Aim of study was to investigate the prevalence of early loss of primary molar teeth and the need for different types of space maintainers in children in the Dravidian population. In this study 3000 Dravidian children between 3 and 10 years of age were examined for early loss of primary molars and the type of space maintainer indicated. The data were obtained from a patient management software and the data were analyzed using Chi-square test. The results indicated that prevalence of early primary molar loss was $32.1 \%$ from 3000 children examined with mean age of $7.8 \pm 1.7$ years with predominance of maxillary first molar (312 teeth) followed by mandibular first molar (298 teeth). Band and loop space maintainer was indicated in 536 children followed by lingual arch space maintainer in 66 children. Conclusion: Based on the findings of this study, the prevalence of early loss of primary molar is $32.1 \%$ with predominance of primary maxillary first molar and the commonly indicated space maintainer is band and loop. Clinical significance: Premature loss of the primary dentition is related to several morpho functional problems, and the utilization of space maintainers may help in the treatment of such problems.
\end{abstract}

KEY WORDS: EARLY LOSS, PREVALENCE, PRIMARY TEETH, SPACE MAINTAINER.

\section{INTRODUCTION}

The primary dentition plays a significant role in the growth and development of the child, in terms of facial aesthetics, phonation, mastication, prevention of deleterious oral habits, development of the dental arches, guidance and eruption of permanent teeth and also harmony of jaws and muscles of the face. Premature loss of primary tooth, principally the molars, may lead to lack of space in the dental arch, malocclusion and midline discrepancies in the permanent dentition. The reduction in arch length reduces the space required for succeeding teeth and thereby predisposes crowding, rotation or impaction of the permanent teeth. These factors accentuate the importance of maintaining them until the normal time of exfoliation (Leite-Cavalcanti et al., 2008; Setia et al., 2013; Christabel and Linda, 2015;

Biosc Biotech Res Comm P-ISSN: 0974-6455 E-ISSN: 2321-4007

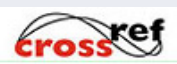

Identifiers and Pagination

Year: 2021 Vol: 14 No (10) Special Issue

Pages: 58-64

This is an open access article under Creative

Commons License Attribn 4.0 Intl (CC-BY). DOI: $h t t p: / / d x$.doi.org/10.21786/bbrc/14.10.10
Gurunathan and Shanmugaavel, 2016; Jeevanandan, 2017; Lakshmanan et al., 2020).

Dental caries, trauma, or early root resorption are the prevailing sources for premature loss of primary teeth. Traumatic dental injuries to the primary teeth will substantially lead to avulsion, premature exfoliation, or extraction due to any complications or feeble prognosis. Primary tooth root resorption is affected by the environmental, hereditary, nutritional, and endocrine factors whereas the root formation of permanent dentition remained undisturbed. The premature loss of primary molars determines the early eruption of permanent teeth if it occurs in an interval close to its normal exfoliation and delay in the eruption of its successors if it occurs at an interval certainly early to that of its normal exfoliation. This is by reason that at the site of loss there is new bone formation on the dental germ, in addition to fibrosis in the gingival tissue due to the trauma caused by mastication. (Sleichter, 1963; Haralabakis et al., 1994; McDonald; 2004; Leite-Cavalcanti et al., 2008; Ahamed et al., 2012; Holan and Needleman, 2014; Govindaraju and Gurunathan, 2017; Packiri et al., 2017; Govindaraju et al., 2017; Panchal et al., 2019; Lakshmanan et al., 2020; Lakshmanan et al., 2020).

Management of space complications associated with the transitional stages from primary to permanent dentition is
Article Information

Received: $08^{\text {th }}$ Aug 2021

Accepted after revision: $19^{\text {th }}$ Oct 2021 
an integral part of pedodontic practice. The post-extraction site has a space loss in the initial few months, primarily due to the distal movement of the primary canine rather than the mesial movement of permanent molar. The rate and extent of space closure in maxilla that develop due to the movement of the teeth distal to the extraction site in a mesial direction is greater than the mandible in which the closure occurs due to distal movement by the teeth present mesial to the extraction site. The earlier the tooth loss, the greater the possibility for drift. Degree of crowding is directly related to the rate and amount of space loss after primary tooth loss. (Baume, 1950; Avramaki et al., 1998; Ibrahim et al., 1995; Cardoso et al., 2005; Jayachandar et al., 2019; Lakshmanan et al., 2020).

In case of premature loss of a primary tooth, it is crucial to fix a space maintainer in order to avoid detrimental impact on the normal development of occlusion, that can lead to future occlusal discrepancies such as arch shortening, mesial inclination of the first molar and impaction of the second premolar or canines, accompanied by rotation, supraeruption of the antagonistic teeth and impairment of the future periodontal support. (Terlaje and Donly, 2001; Da-Costa et al., 2019; Lakshmanan et al., 2020).

These complications can be prevented or their severity can be alleviated if the dentist performs appropriate planning and utilizes space maintainer during initial treatment in the mixed dentition. Various types of appliances are used as space maintainers, depending on the dental developmental stage, dental arch status, the number, location and type of primary teeth involved and also based on the child's cooperative ability. Previously our team has a rich experience in working on various research projects across multiple disciplines. Now the growing trend in this area motivated us to pursue this project. (Ke et al., 1938; Ramakrishnan et al., 2019; Sharma et al., 2019; Varghese et al., 2019; Venu et al., 2019; Samuel et al., 2019; Mehta et al., 2019; Gheena and Ezhilarasan, 2019; Venu et al., 2019; Vignesh et al., 2019; Malli et al., 2019; Vijayakumar et al., 2019; Sathish and Karthick, 2020; Samuel et al., 2020; Krishnaswamy et al., 2020; Muthukrishnan et al., 2020; Jose et al., 2020).

The purpose of the current study was to investigate the prevalence of early loss of primary molar teeth and the need for space maintainers in Dravidian children between 3 to 10 years of age.

\section{MATERIAL AND METHODS}

This cross-sectional study was conducted in a university setting. The ethical clearance was obtained from the Institutional Review Board prior to the start of the study (SDC/SIHEC/2020/DIASDATA/0619-0320). Dental records of 3,000 children who had visited the department for extraction from June 2019 to April 2020 were retrospectively examined by a single examiner. Healthy children aged between 3 to 10 years and only children of Dravidian origin were chosen for the study. The data were collected from an existing patient management software and details obtained from the patient records were as follows: age and gender of the child, type and number of teeth lost and type of space maintainer indicated.

Statistical analysis: The data were tabulated into a spreadsheet (Excel 2017: Microsoft office) and statistical analysis was done using SPSS software 17.0 version (SPSS Inc., Chicago, IL, USA). Descriptive statistics and Chi-square tests were performed to compare the obtained results.

Figure 1: Image represents the correlation of early loss of primary molar teeth and the type of tooth loss, where $\mathrm{X}$-axis denotes the type of teeth and $\mathrm{Y}$-axis denotes the type of tooth loss. Blue denotes unilateral loss and red denotes bilateral loss. Both unilateral loss and bilateral loss were most seen in primary maxillary 1st molar followed by primary mandibular 1 st molar and statistically significant difference was obtained on comparing the type of tooth loss and the type of teeth (Chi-square test; $P=0.02$ - statistically significant).

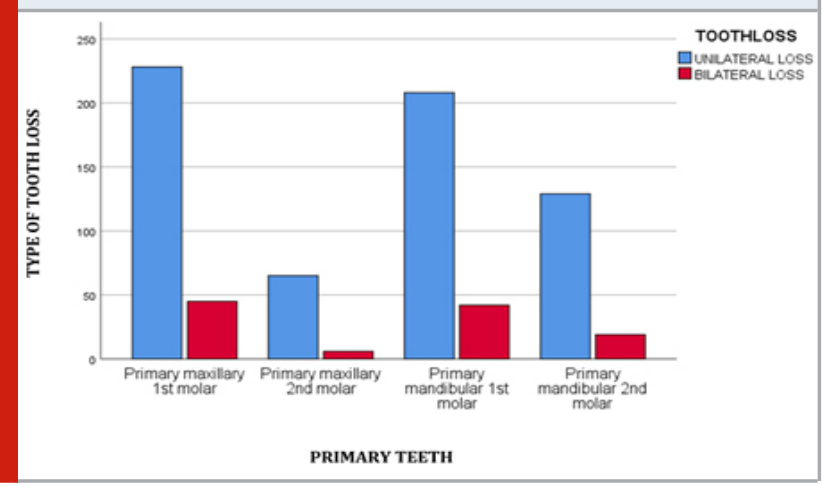

Figure 2: Image represents the correlation of type of space maintainer indicated in relation to the loss of primary molar teeth, where $\mathrm{X}$-axis denotes the type of teeth and Y-axis denotes the type of space maintainer. Blue denotes band and loop, red denotes reverse band and loop, dark green denotes crown and loop, orange denotes nance, yellow denotes transpalatal arch, and light green denotes lingual arch. Band and loop were the most indicated space maintainer in case of early loss of any primary molars which was statistically significant (Chi-square test; $P$ value $=0.01$ statistically significant).

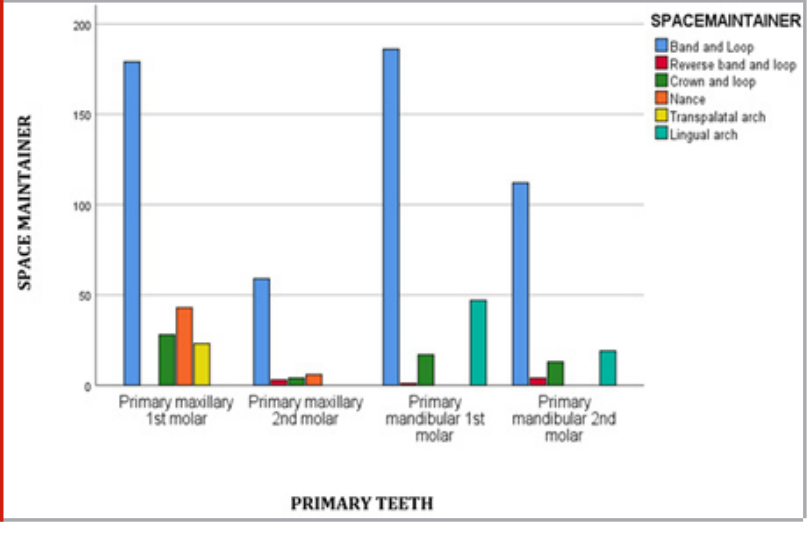




\section{RESULTS AND DISCUSSION}

In this study, the prevalence of early loss of primary molar teeth was $32.1 \%$ (963 teeth) from 3,000 children (males1520 ; females- 1480) examined with mean age of $7.8 \pm 1.7$ years with predominance of primary maxillary first molar (32.4\%), followed by primary mandibular first molar (31\%), mandibular second molar (24\%) and maxillary second molar $(12.6 \%)$. These differences were statistically significant $(\mathrm{P}<0.05)$ (Table 1). Unilateral loss $(65 \%)$ was observed to be more than the bilateral loss $(35 \%)$ with statistically significant difference $(\mathrm{P}<0.05)$ (Table 2) (Figure 1).

Table 1. Comparison of early loss of primary molar teeth showing a higher prevalence of primary maxillary first molar (32.4\%) followed by primary mandibular first molar (31\%) and statistically significant difference was noted on comparing all the teeth. (Chi-square test; P-value=0.02statistically significant).

\begin{tabular}{|c|c|c|c|}
\hline $\begin{array}{l}\text { Primary tooth } \\
\text { lost }\end{array}$ & $\begin{array}{l}\text { Number } \\
\text { of teeth }\end{array}$ & Percentage & P value \\
\hline $\begin{array}{l}\text { Primary maxillary } \\
1^{\text {st }} \text { molar }\end{array}$ & 312 & 32.4 & 0.02 \\
\hline $\begin{array}{l}\text { Primary mandibular } \\
1{ }^{\text {st }} \text { molar }\end{array}$ & 298 & 31.0 & \\
\hline $\begin{array}{l}\text { Primary mandibular } \\
2^{\text {nd }} \text { molar }\end{array}$ & 231 & 24.0 & \\
\hline $\begin{array}{l}\text { Primary maxillary } \\
2^{\text {nd }} \text { molar }\end{array}$ & 122 & 12.6 & \\
\hline Total & 963 & 100 & \\
\hline
\end{tabular}

Table 2. Comparison of location of tooth loss (Unilateral or Bilateral) showing a higher prevalence of unilateral loss $(65 \%)$ followed by bilateral loss $(35 \%)$ that was statistically significant. (Chi square test; $P=0.02$-statistically significant).

\begin{tabular}{|l|c|c|c|}
\hline Type of tooth loss & No. of cases & Percentage & P value \\
\cline { 1 - 2 } Unilateral loss & 630 & $65 \%$ & 0.02 \\
\hline Bilateral loss & 112 & $35 \%$ & \\
\hline
\end{tabular}

Band and loop space maintainer was indicated in 536 children, followed by lingual arch in 66 children. The least indicated space maintainer was the reverse band and loop ( 8 children). Table 3 shows the types of space maintainers indicated in children and (Figure 2) depicts the distribution of type of space maintainer indicated in relation to the early loss of primary molar teeth. The effect of early loss of primary teeth on the development of the dentition is an element of great interest. The loss of a primary tooth is mediated to be premature when it occurs at least one year earlier its normal exfoliation or after radiographic evidence that the permanent successor is still short of Nolla stage six coronary formation and root formation not yet started. (Terlaje and Donly, 2001; Somasundaram et al., 2015;
Jeevanandan and Govindaraju, 2018; Lakshmanan and Gurunathan, 2019).

Table 3. Comparison of different types of space maintainers indicated in relation to the number of children with early loss of primary tooth, where band and loop was indicated in 536 children followed by lingual arch in 66 children. Statistically significant difference was obtained on comparing the types of space maintainers indicated. (Chisquare test; $p$ value $=0.01$ - statistically significant).

\begin{tabular}{|l|c|c|}
\hline Types of space maintainers & No. of Children & \multirow{2}{*}{ P value } \\
Band and loop & 536 & \multirow{2}{*}{0.01} \\
\hline Lingual arch & 66 & \\
\hline Crown and loop & 62 & \\
\hline Nance palatal arch & 49 & \\
\hline Transpalatal arch & 23 & \\
\hline Reverse band and loop & 8 & \\
\hline
\end{tabular}

The premature loss of primary teeth was reported to be responsible for an earlier eruption of permanent successors and intervenes with the harmony of permanent dentition resulting in crowding induced by shifting and / or drifting of teeth toward the extraction space. Furthermore, psychological, morphological, esthetical and functional problems may develop from premature loss of primary teeth. The prevalence of premature loss of primary teeth in children has been previously chartered in a bunch of researches around the world. The current study consisted of screening a total number of 3,000 Dravidian children aged between 3-10 years, of which 1520 were boys (51\%) and 1480 were girls (49\%) (Saloom, 2005; Ravikumar et al., 2017; Govindaraju et al., 2017).

Since almost an equivalent number of male and female children were chosen for the study the findings of the study are not biased due to gender inaccuracy. Furthermore, the present study being conducted in an ethnically homogeneous community, could act as a reference for understanding the prevalence of early loss of primary teeth in Dravidian population which necessitates the action to be started for the prevention of early childhood caries among children. The children screened were from diverse socioeconomic status so that there is an outright distribution of children attached to various grades of society. It has been endorsed that child belonging to lower socioeconomic status have a higher incidence of dental caries (Sudha et al., 2006; Saravanan et al., 2008; Subramanyam et al., 2018).

Souza et al., 2016 stated that the major etiological component for the early loss of primary teeth was dental caries that were neglected due to socioeconomic problems and lack of knowledge regarding the importance of primary teeth. The possibility of tooth loss should also be considered due to the hypomineralization of the primary molars, since this deformity does not involve only the permanent incisors and molars, but also the primary molars, which may advance the carious lesion and consequently result in the tooth loss 
according to the literature. The increased prevalence of early loss of primary teeth in children may be due to the fact that many general dentists prefer to extract a carious primary tooth rather than restoring it, and it could also be attributed to the parent's knowledge and attitude regarding the extraction of primary teeth as they recognize that the teeth will eventually get replaced (Cavalcanti et al., 2008; Da-Costa et al., 2010; Silva et al., 2010; De-Souza et al., 2016; Da-Costa et al., 2019; Jayachandar et al., 2019).

The primary maxillary first molar $(32.4 \%)$ followed by mandibular first molar (31\%) are the most common teeth affected by premature loss, which is in accordance to the studies conducted by Cavalcanti et al.(2015), and Jayachandar et al.(2019), This outcome can be ascribed to the chronologic age of eruption of the first and second primary molars. The primary first molars which erupt earlier, abide in the oral environment for a longer duration and are ultimately more prone to dental caries. Furthermore, as the distal surface of primary second molar guides the erupting permanent first molar to adequately occlude the antagonist, dentists commonly would prefer to restore a primary second molar rather than extracting the tooth. This could be regarded as one of the reasons for increased prevalence of early loss of primary first molars than second molars. (Kobylińska et al., 2015; Cavalcanti et al.,2015; Jayachandar et al., 2019).

Cardoso et al., (2005) reported the prevalence of premature loss of primary molars to be $54.6 \%$ in Brazillian children, da Costa et al., reported it to be $4.04 \%$ and Ahamed et al., stated the prevalence to be $16.5 \%$ in Indian children that contrast with the current study (32.1\%). These differences could be attributed to the different sample size and criteria of the studies. One of the enormous challenges in pediatric dentistry is the management of space loss due to untimely loss of primary teeth. Various appliances can be used for maintaining the space based on the patient's age, status of dental arches and ability to cooperate for the treatment (Ahamed et al., 2012; Da-Costa et al., 2019).

The frequently indicated space maintainer in the current study is the band and loop, which is a non-functional fixed space maintainer indicated for non-collaborative patients, in cases where the premature loss is preferably unilateral. Band and loop space maintainer provided satisfactory results in terms of its survival rate, hygienization, cost factor and dentists cited it to be easy in fabrication, installation and removal of the appliance. Whereas the least indicated space maintainer in the present study is the reverse band and loop that is determined in case of premature loss of primary second molar where the support from permanent first molar is not suitable. For the bilateral loss of molars, the commonly indicated space maintainer is lingual arch followed by nance palatal arch and transpalatal arch depending on the clinical condition. (Setia, 2013; Watt et al., 2018; Chandra et al., 2018; Ramakrishnan et al., 2019).

The shortcomings of the present study were, the reason for specific space maintainers were not included and the treatment plan was not decided by a single operator. In future, long-term studies examining the longevity of different types of space maintainers could be carried out. Our institution is passionate about high quality evidence based research and has excelled in various fields ( Ramesh et al., 2018; Pcet al., 2018; Vijayashree, 2019; Ezhilarasan et al., 2019; Sridharan et al., 2019; Ramadurai et al., 2019; Mathew et al., 2020). We hope this study adds to this rich legacy.

\section{CONCLUSION}

In the light of available evidence, the prevalence of premature loss of primary molar teeth was $32.1 \%$ with predominance of primary first molar. Unilateral loss was more prevalent than bilateral loss and the commonly indicated space maintainer was band and loop.

Clinical Significance: Premature loss of the primary dentition is related to several morphofunctional problems, and the utilization of space maintainers may help in the treatment of such problems.

\section{ACKNOWLEDGEMENTS}

The authors of the current study acknowledge the university for providing the patient's clinical records as required for the successful completion of the study.

\section{REFERENCES}

Setia V, Pandit IK, Srivastava N, Gugnani N, Sekhon HK. (2013). Space maintainers in dentistry: past to present. J Clin Diagn Res. Oct;7(10):2402-5.

Gurunathan D, Shanmugaavel AK. (2016). Dental neglect among children in Chennai. J Indian Soc Pedod Prev Dent. 34(4):364-9.

Jeevanandan G. (2017). Kedo-S Paediatric Rotary Files for Root Canal Preparation in Primary Teeth - Case Report. J Clin Diagn Res.11(3): ZR03-5.

Christabel SL, Linda Christabel S. (2015). Prevalence of Type of Frenal Attachment and Morphology of Frenum in Children, Chennai, Tamil Nadu [Internet]. Vol. 6, World Journal of Dentistry.. p. 203-7. Available from: http:// dx.doi.org/10.5005/jp-journals-10015-1343

Cavalcanti L A, de Alencar B, Benzerra PK, Garcia A. (2008). Prevalence of early loss of primary molars in school children in Brazil. Pak Oral Dent J.; 28:113-6. Haralabakis NB, Yiagtzis SC, Toutountzakis NM. (1994). Premature or delayed exfoliation of deciduous teeth and root resorption and formation. Angle Orthod.;64(2):151-7.

Lakshmanan L, Mani G, Jeevanandan G. (2020). Assessing the quality of root canal filling and instrumentation time using kedo-s files, reciprocating files and k-files. Braz Dent J [Internet].; Available from: https://bds.ict.unesp.br/index. php/cob/article/view/1822

Govindaraju L, Gurunathan D. (2017). Effectiveness of Chewable Tooth Brush in Children-A Prospective Clinical Study. J Clin Diagn Res. 11(3): ZC31-4.

Holan G, Needleman HL. (2014). Premature loss of 
primary anterior teeth due to trauma--potential short-and long-term sequelae. Dent Traumatol.;30(2):100-6.

Packiri S, Gurunathan D, Selvarasu K. (2017). Management of Paediatric Oral Ranula: A Systematic Review. J Clin Diagn Res. 11(9): ZE06-9.

McDonald RE, Avery DR, Dean JA. (2004). Eruption of teeth: local, systemic, and congenital factors that influence the child and adolescent. U: McDonald RE, Avery DR, Dean JA, ur Dentistry for the child and adolescent. 8:174-202.

Govindaraju L, Jeevanandan G, Subramanian E. (2017). Clinical Evaluation of Quality of Obturation and Instrumentation Time using Two Modified Rotary File Systems with Manual Instrumentation in Primary Teeth. J Clin Diagn Res. 11(9): ZC55-8.

Panchal V, Jeevanandan G. (2019). Comparison of instrumentation time and obturation quality between hand K-file, H-files, and rotary Kedo-S in root canal treatment of primary teeth: A Journal of Indian Society Available from: http://www.jisppd.com/article.asp?issn=0970-438 8 ; year $=2019 ;$ volume $=37 ;$ issue $=1 ;$ spage $=75 ;$ epage $=79 ;$ a ulast=Panchal

Ahamed SSS, Reddy VN, Krishnakumar R, Mohan MG, Sugumaran DK, Rao AP. (2012). Prevalence of early loss of primary teeth in 5-10-year-old school children in Chidambaram town. Contemp Clin Dent. 2012 Jan;3(1):27-30.

Sleichter GG. (1963). The influence of premature loss of deciduous molars and the eruption of their successors. Angle Orthod. 33(4):279-83.

Jayachandar D, Gurunathan D, Jeevanandan G. (2019). Prevalence of early loss of primary molars among children aged 5-10 years in Chennai: A cross-sectional study. J Indian Soc Pedod Prev Dent. 1;37(2):115.

Ibrahim Masoud BDS. (1995). Prevalence and distribution of caries in the primary dentition in a cosmopolitan Saudi population. Saudi dental journal [Internet]. 1995;7(1). Available from: https://www.researchgate. net/profile/Najlaa_Alamoudi2/publication/268395660_ Prevalence_and_distribution_of_caries_in_the_primary dentition_in_a_Cosmopolitan_Saudi_Population/ links/553c7ef80cf245bdd7668b8a.pdf

Cardoso L, Zemburski C, Fernandes DS. (2005). Evaluation of prevalence of precocious loss of desiduous molars. Braz Res Pediatr Dent Integr Clin. 5:17-22.

Avramaki, E. (1988). The effect of balanced and unbalanced extraction of primary molars on the relationship of incisor centreline-a pilot study. J Paediatr Dent. 4:9-12.

Baume LJ. (1950). Physiological tooth migration and its significance for the development of occlusion. I. The biogenetic course of the deciduous dentition. J Dent Res. 29(2):123-32.

Terlaje RD, Donly KJ. (2001). Treatment planning for space maintenance in the primary and mixed dentition. ASDC J Dent Child. 68(2):109-14, 80.

da Costa AL, da Fonseca GHA, da Silva NRF, de Jesus Martins KR, Others. (2019). Deciduous tooth early loss prevalence in posterior region and indication of band-loop space maintainer. Brazilian Dental Science. 22(3):321-8.

Ramakrishnan M, Dhanalakshmi R, Subramanian EMG. (2019). Survival rate of different fixed posterior space maintainers used in Paediatric Dentistry - A systematic review. Saudi Dent J. 31(2):165-72.

Sathish T, Karthick S. (2020). Wear behaviour analysis on aluminium alloy 7050 with reinforced $\mathrm{SiC}$ through taguchi approach. J Jpn Res Inst Adv Copper-Base Mater Technol. 9(3):3481-7.

Varghese SS, Ramesh A, Veeraiyan DN. (2019). Blended Module-Based Teaching in Biostatistics and Research Methodology: A Retrospective Study with Postgraduate Dental Students. J Dent Educ. 83(4):445-50.

Samuel SR, Acharya S, Rao JC. (2020). School Interventions-based Prevention of Early-Childhood Caries among 3-5-year-old children from very low socioeconomic status: Two-year randomized trial. J Public Health Dent. 80(1):51-60.

Venu H, Raju VD, Subramani L. (2019). Combined effect of influence of nano additives, combustion chamber geometry and injection timing in a DI diesel engine fuelled with ternary (diesel-biodiesel-ethanol) blends. Energy. 174:386-406.

Samuel MS, Bhattacharya J, Raj S, Santhanam N, Singh H, Pradeep Singh ND. (2019). Efficient removal of Chromium (VI) from aqueous solution using chitosan grafted graphene oxide (CS-GO) nanocomposite. Int J Biol Macromol. 121:285-92.

Venu H, Subramani L, Raju VD. (2019). Emission reduction in a DI diesel engine using exhaust gas recirculation (EGR) of palm biodiesel blended with $\mathrm{TiO} 2$ nano additives. Renewable Energy. 140:245-63.

Mehta M, Deeksha, Tewari D, Gupta G, Awasthi R, Singh $\mathrm{H}$, et al. (2019). Oligonucleotide therapy: An emerging focus area for drug delivery in chronic inflammatory respiratory diseases. Chem Biol Interact. 1; 308:206-15. Sharma P, Mehta M, Dhanjal DS, Kaur S, Gupta G, Singh H, et al. (2019). Emerging trends in the novel drug delivery approaches for the treatment of lung cancer. Chem Biol Interact. 25; 309:108720.

Malli Sureshbabu N, Selvarasu K, V JK, Nandakumar M, Selvam D. (2019). Concentrated Growth Factors as an Ingenious Biomaterial in Regeneration of Bony Defects after Periapical Surgery: A Report of Two Cases. Case Rep Dent.22;2019:7046203.

Krishnaswamy H, Muthukrishnan S, Thanikodi S, Arockiaraj G Antony, Venkatraman V. (2020). Investigation 
of air conditioning temperature variation by modifying the structure of passenger car using computational fluid dynamics. Therm Sci. 4(1 Part B):495-8.

Muthukrishnan S, Krishnaswamy H, Thanikodi S, Sundaresan D, Venkatraman V. (2020). Support vector machine for modelling and simulation of heat exchangers. Therm Sci.;24(1 Part B):499-503.

Gheena S, Ezhilarasan D. (2019). Syringic acid triggers reactive oxygen species-mediated cytotoxicity in HepG2 cells. Hum Exp Toxicol. 38(6):694-702.

Vignesh R, Sharmin D, Rekha CV,Annamalai S, Baghkomeh PN. (2019). Management of Complicated Crown-Root Fracture by Extra-Oral Fragment Reattachment and Intentional Reimplantation with 2 Years Review. Contemp Clin Dent.10(2):397-401.

Ke Y,AlAboody MS, Alturaiki W, Alsagaby SA, Alfaiz FA, Veeraraghavan VP, et al. (2019). Photosynthesized gold nanoparticles from Catharanthus roseus induces caspasemediated apoptosis in cervical cancer cells (HeLa). Artif Cells Nanomed Biotechnol. 47(1):1938-46.

Vijayakumar Jain S, Muthusekhar MR, Baig MF, Senthilnathan P, Loganathan S, Abdul Wahab PU, et al. (2019). Evaluation of Three-Dimensional Changes in Pharyngeal Airway Following Isolated Lefort One Osteotomy for the Correction of Vertical Maxillary Excess: A Prospective Study. J Maxillofac Oral Surg. 18(1):139-46.

Jose J, Ajitha, Subbaiyan H. (2020). Different treatment modalities followed by dental practitioners for Ellis class 2 fracture - A questionnaire-based survey. Open Dent J. 18;14(1):59-65.

Somasundaram S, Ravi K, Rajapandian K, Gurunathan D. (2015). Fluoride Content of Bottled Drinking Water in Chennai, Tamilnadu. J Clin Diagn Res.9(10): ZC32-4.

Jeevanandan G, Govindaraju L. (2018). Clinical comparison of Kedo-S paediatric rotary files vs manual instrumentation for root canal preparation in primary molars: a double blinded randomised clinical trial. Eur Arch Paediatr Dent. 19(4):273-8.

Lakshmanan L, Gurunathan D. (2019). Prevalence of congenitally missing second premolar teeth in the Dravidian population. J Forensic Dent Sci. 11(2):103-6. Saloom HF. (2005). Early loss of deciduous teeth and occlusion. Iraqi Orthod Journal.;1(2):36-9.

Ravikumar D, Jeevanandan G, Subramanian EMG. (2017). Evaluation of knowledge among general dentists in treatment of traumatic injuries in primary teeth: A crosssectional questionnaire study. Eur J Dent. 11(2):232-7. Govindaraju L, Jeevanandan G, Subramanian EMG. (2017). Knowledge and practice of rotary instrumentation in primary teeth among indian dentists: A questionnaire survey. Journal of International Oral Health. 1;9(2):45.

Subramanyam D, Gurunathan D, Gaayathri R, Vishnu
Priya V. (2018). Comparative evaluation of salivary malondialdehyde levels as a marker of lipid peroxidation in early childhood caries. Eur J Dent. 12(1):67-70.

Saravanan S, Kalyani V, Vijayarani MP, Jayakodi P, Felix JWA, Arunmozhi P, et al. (2008). Caries prevalence and treatment needs of rural school children in Chidambaram Taluk, Tamil Nadu, South India [Internet]. Vol. 19, Indian Journal of Dental Research. p. 186. Available from: http:// dx.doi.org/10.4103/0970-9290.42948

Sudha P, Kulkarni SS, Anegundi R, Mahejabeen R. (2006). Dental caries prevalence among preschool children of Hubli: Dharwad city [Internet]. Vol. 24, Journal of Indian Society of Pedodontics and Preventive Dentistry. p. 19. Available from: http://dx.doi.org/10.4103/09704388.22829

de Souza RA, de Araújo Magnani MBB, Nouer DF, Romano FL, Passos MR. (2016). Prevalence of malocclusion in a brazilian schoolchildren population and its relationship with early tooth loss. Brazilian Journal of Oral Sciences. $12 ; 1566-70$

da Costa-Silva CM, Jeremias F, de Souza JF, De CÁSSIA LOIOLA CORDEIRO R, Santos-Pinto L, Cilense Zuanon AC. (2010). Molar incisor hypomineralization: prevalence, severity and clinical consequences in Brazilian children. Int J Paediatr Dent. 20(6):426-34.

Silva MJ, Scurrah KJ, Craig JM, Manton DJ, Kilpatrick N. (2016). Etiology of molar incisor hypomineralization-a systematic review. Community Dent Oral Epidemiol. 44(4):342-53.

Govindaraju L, Jeevanandan G, Subramanian EMG. (2017). Comparison of quality of obturation and instrumentation time using hand files and two rotary file systems in primary molars: A single-blinded randomized controlled trial. Eur J Dent. 11(03):376-9.

Cavalcanti AL, Alencar C, Bezerra P, Granville-Garcia AF. (2008). Prevalence of early loss of primary molars in school children in Campina Grande, Brazil. Pak Oral Dent J. 28(1):113-6.

Kobylińska A, Borawska J, Chojnowska A, Janczewska J, Turska-Szybka A, Olczak-Kowalczyk D. (2015). Frequency and causes of premature extractions of deciduous molar teeth - a retrospective study [Internet]. Vol. 20, Nowa Stomatologia. p. 3-9. Available from: http:// dx.doi.org/10.5604/14266911.1154071

Setia V. (2013). Space Maintainers in Dentistry: Past to Present [Internet]. JOURNAL OF CLINICAL AND DIAGNOSTIC RESEARCH. Available from: http:// dx.doi.org/10.7860/jcdr/2013/6604.3539

Watt E, Ahmad A, Adamji R, Katsimpali A, Ashley P, Noar J. (2018). Space maintainers in the primary and mixed dentition - a clinical guide. Br Dent J. 24;225(4):293-8. Chandra HS, Sharath Chandra H, Krishnamoorthy SH, Johnson JS, Prabhu S. ILL (2018). effects of Conventional 
band and loop space maintainers: Time to revolutionise [Internet]. Vol. 4, International Dental \& Medical Journal of Advanced Research - VOLUME. p. 1-3. Available from: http://dx.doi.org/10.15713/ins.idmjar.83

Vijayashree Priyadharsini J. (2019). In silico validation of the non-antibiotic drugs acetaminophen and ibuprofen as antibacterial agents against red complex pathogens. J Periodontol. 90(12):1441-8.

Ezhilarasan D, Apoorva VS, Ashok Vardhan N. (2019). Syzygium cumini extract induced reactive oxygen speciesmediated apoptosis in human oral squamous carcinoma cells. J Oral Pathol Med. 48(2):115-21.

Ramesh A, Varghese S, Jayakumar ND, Malaiappan S. (2018). Comparative estimation of sulfiredoxin levels between chronic periodontitis and healthy patients - A case-control study. J Periodontol. 89(10):1241-8.

Mathew MG, Samuel SR, Soni AJ, Roopa KB. (2020).
Evaluation of adhesion of Streptococcus mutans, plaque accumulation on zirconia and stainless steel crowns, and surrounding gingival inflammation in primary. Clin Oral Investig [Internet]. Available from: https://link.springer. com/article/10.1007/s00784-020-03204-9

Sridharan G, Ramani P, Patankar S, Vijayaraghavan R. (2019). Evaluation of salivary metabolomics in oral leukoplakia and oral squamous cell carcinoma. J Oral Pathol Med. 48(4):299-306.

Pc J, Marimuthu T, Devadoss P. (2018). Prevalence and measurement of anterior loop of the mandibular canal using CBCT: A cross sectional study. Clin Implant Dent Relat Res [Internet]. Available from: https://europepmc. org/article/med/29624863

Ramadurai N, Gurunathan D, Samuel AV, Subramanian E, Rodrigues SJL. (2019). Effectiveness of 2\% Articaine as an anesthetic agent in children: randomized controlled trial. Clin Oral Investig. ;23(9):3543-50. 